\title{
Market Definition, Market Power
}

\section{Citation}

Louis Kaplow, Market Definition, Market Power (Harvard John M. Olin Discussion Paper Series Paper No. 826, May 2015).

\section{Published Version}

http://www.law.harvard.edu/programs/olin_center/papers/pdf/Kaplow_826.pdf

\section{Permanent link}

http://nrs.harvard.edu/urn-3:HUL.InstRepos:17742179

\section{Terms of Use}

This article was downloaded from Harvard University's DASH repository, and is made available under the terms and conditions applicable to Other Posted Material, as set forth at http:// nrs.harvard.edu/urn-3:HUL.InstRepos:dash.current.terms-of-use\#LAA

\section{Share Your Story}

The Harvard community has made this article openly available.

Please share how this access benefits you. Submit a story.

\section{Accessibility}




\section{HARVARD}

JOHN M. OLIN CENTER FOR LAW, ECONOMICS, AND BUSINESS

\section{MARKET DEFINITION, MARKET POWER}

Louis Kaplow

Forthcoming in the International Journal of Industrial Organization

Discussion Paper No. 826

$05 / 2015$

Harvard Law School

Cambridge, MA 02138

This paper can be downloaded without charge from:

The Harvard John M. Olin Discussion Paper Series: http://www.law.harvard.edu/programs/olin_center/

The Social Science Research Network Electronic Paper Collection:

http://ssrn.com/abstract=2605179 


\title{
MARKET DEFINITION, MARKET POWER
}

\section{Louis Kaplow*}

\begin{abstract}
Market definition and market power are central features of competition law and practice but pose serious challenges. On one hand, market definition suffers decisive logical infirmities that render it infeasible, unnecessary, and counterproductive, and the practice of stating market power requirements as market share threshold tests is incoherent as a matter of empirics and policy. On the other hand, market power is often probative of the desirability of liability, yet the typically assumed functional relationship is unexplored and often implausible. These latter deficiencies are addressed through a ground-up analysis of the channels by which market power can be relevant. It is important to explicitly and simultaneously consider both anticompetitive and procompetitive explanations for challenged practices and to attend to the magnitudes of the social consequences of correct and mistaken imposition of liability in order to identify the various ways and senses in which market power bears on optimal decision-making.
\end{abstract}

Keywords: market power, market definition, competition policy, antitrust, merger guidelines, market share

JEL Classification: D42, K21, L12, L40

Forthcoming, International Journal of Industrial Organization

(C) Louis Kaplow. All rights reserved.

\footnotetext{
*Harvard University and National Bureau of Economic Research. I thank the editor for comments and Harvard University’s John M. Olin Center for Law, Economics, and Business for financial support. Section 2 draws heavily on Kaplow (2010, 2011a, 2011b); section 3 presents preliminary results from an ongoing project, "On the Relevance of Market Power"; and all is anticipated to be reformulated as a book tentatively entitled "Market Definition, Market Power, and Competition Policy.” Disclaimer: I occasionally consult on antitrust cases, and my spouse is in the legal department of a financial services firm.
} 


\section{Introduction}

This article explores market definition and market power - the latter of which, as we will see, is deeply entangled with most other issues in the field of competition policy. The aim is to build a bridge between industrial organization economics research and the realm of competition policy and practice. It is hoped that industrial organization economics can do more to inform competition regulation: its rules and guidance as well as its application in particular cases. In order to do so, it is necessary to identify more explicitly the most relevant lines of research, which task requires asking and attempting to answer a number of neglected questions. Although a healthy two-way interaction between industrial organization economics and competition policy has existed for decades, many gaps remain.

Some of the problems are suggested by a few simple, high-level conundrums: Competition law often demands defining a market, and economists at competition agencies and consulting for private parties purport to define markets routinely, yet the concept of market definition does not really exist in industrial organization economics. Competition law employs market power tests in the form of market share thresholds, yet it is impossible to give economic meaning to such thresholds in terms of market power. Competition guidelines, such as those governing horizontal mergers, profess to target price increases, yet they do not say what price increase is being targeted or identify how any such target is related to the Herfindahl-Hirschman Index (HHI) thresholds that are offered. And, perhaps most important, competition law and guidance often determine liability as a function of two variables - market power and the degree of evidenced undesirability of the action under scrutiny - yet the functional relationship is never defined, is not grounded in models, and is not related to empirical evidence.

In short, the most central questions concerning market definition, market power, and related matters are rarely asked, much less answered. Closer inspection reveals that myriad subsidiary issues are likewise hidden despite their importance. This article sketches a way forward. Some of the path is intuitive and largely involves making concrete what we often are doing implicitly when conducting industrial organization research. Even in these more satisfactory areas, however, the proper understanding is not well aligned with competition policy statements, including those that have benefited from substantial input by economists. More problematic, in many other respects there are large - and largely unrecognized - chasms that require additional research. In many instances, the proper analysis not only diverges from conventional wisdom but operates on a different plane, and occasionally it is in opposition to what we ordinarily suppose.

This article first considers the relationship between market definition and market share, on one hand, and market power, on the other hand, and next assesses the appropriate role of market power in competition policy. As a logical matter, the opposite order is appealing since the reasons we might care about market power bear on its proper meaning(s) and, accordingly, on how best to measure it. Nevertheless, this article begins with the market definition / market power paradigm because it is conventional and familiar - and the proper understanding of this paradigm, I will argue (drawing on Kaplow 2010, 2011a, 2011b), is fairly clear on reflection, although it conflicts with conventional wisdom and practice. The proper role of market power, by contrast, is more complex and does not lend itself to a single answer. This subject is the focus of ongoing research, aspects of which are highlighted here. 


\subsection{Market Definition, Market Share, and Market Power}

Section 2 addresses fundamental infirmities in the standard paradigm for establishing market power - the definition of a so-called relevant market for purposes of making inferences about market power from market shares therein - and also the use of market shares in stating legal tests pertaining to market power. There are two logical defects in the market definition paradigm. First, one cannot infer market power from market shares in "redefined" (nonhomogeneous goods) markets. Because the purpose of market definition is to make inferences about market power from such market shares, the impossibility of doing so in an economically valid manner makes it difficult to rationalize standard practice. Second, it is impossible to choose which market definition is best without already having in hand a best estimate of market power. This point renders the market definition exercise circular. Worse, using market definition and attempting to make market power inferences from the market shares in the relevant market throws away information and thereby results in inferior inferences.

Both of these problems are illustrated by examining the most-analyzed applications of the paradigm: the assessment of horizontal mergers using the hypothetical monopolist test (HMT). Market definition is unnecessary and affirmatively counterproductive in the three standard settings: unilateral effects in homogeneous goods markets, unilateral effects in differentiated products markets, and coordinated effects. Moreover, it is shown, via an example in a basic setting, that the guidelines approach can mis-order mergers despite differences in price effects exceeding thirty-five to one.

Finally, market share threshold tests - for example, stating that a $50 \%$ share is presumptively required for abuse of dominance, or using HHIs in merger guidelines - are also incoherent. Such tests conflate empirical and policy questions, and the use of market shares does not properly address either question.

\subsection{The Role of Market Power in Competition Policy}

Section 3 sets aside concerns about market power measurement and the problematic embrace of market shares for various purposes and turns to the role of market power in assessing liability. The analysis focuses primarily on identifying different types of unexamined questions and then sketching suggestive lines of inquiry that may better guide competition policy and practice as well as research in industrial organization economics.

To begin, it is helpful to state some of these questions. First, market power is posited as an "element" in many competition law offenses. What does this mean in terms of the functional relationship between evidence on market power and that on the acts under scrutiny? And does it make sense? Indeed, is it plausible to state such a reduced-form function for most types of practices? Second, market power is widely regarded to be relevant in assessing most allegedly anticompetitive acts. But what, exactly, are the channels of influence? Does the attractiveness of assigning liability broadly increase in the extent of market power, or only sometimes? And when? Third, market power can mean different things. Does it refer to levels (and, if so, with or without the practice), to deltas (changes in market power), or to something else? Is the answer the same across practices and, for a given practice, for each channel of possible relevance? Fourth, can one coherently assess the desirability of liability for an act alleged to have character $X$ without explicitly articulating the relevant alternative explanation $X^{\prime}$ ? And how does market power affect the plausibility and magnitude of $X^{\prime}$ ? 
Many of these questions are not explicitly addressed by existing work in industrial organization economics or in competition agency statements. Answers can be offered, but many are different from what has long been contemplated and most need substantial further development on both theoretical and empirical fronts.

Section 3 will specify more precisely what it means to say that liability is a function of two elements, one concerning market power and the other the nature of the act in question. It will be explained that, on its face, the standard formulation embodies a lexicographic function that is implausible. Moreover, it entails an important separability assumption that seems dubious for many applications.

Next, the analysis moves to an affirmative construction. It begins by focusing on the classification channel: that is, market power may be relevant because it helps us determine the likelihood that a challenged act has anticompetitive and procompetitive effects, whether understood in terms of consumer or total welfare. The appropriate analysis, therefore, is often comparative, yet agency publications on abuse of dominance (in the United States, on monopolistic practices) not only silo discussions of market power and practices but also, when examining practices, largely compartmentalize the analysis of anticompetitive effects and procompetitive justifications. Also important, but more neglected, is the possibility that market power may be relevant to decision-making about liability because it affects the magnitude of social harm (conditional on the act being anticompetitive) and also of the social loss from the mistaken imposition of liability (conditional on the act being procompetitive).

The meaning of market power will also be investigated more explicitly. Sometimes (such as in stating the market share threshold for abuse of dominance), market power requirements refer to levels. In such instances, it is not always clear whether the pertinent level is that with or without the practice. Other times, market power apparently refers to deltas (changes in levels). And sometimes - which seems standard in horizontal merger guidelines that refer to post-merger HHIs and also to changes in HHIs in formulating danger zones and safe harbors - there is reference to both levels and deltas. Some discussion is offered here concerning which senses of market power may be relevant in various settings.

Viewing the analysis as a whole, it will be seen that market power is not always relevant in these senses and through these various channels, that the strength of any pertinent association varies greatly across contexts, and that occasionally the sign on certain channels may be reversed (that is, greater market power may make liability less attractive). In short, whether, why, and how market power in different guises proves to be important varies tremendously - not just across offense types (mergers versus monopolization) or standard categories of acts (predatory pricing versus exclusive dealing), but across industry settings and possible procompetitive explanations. A few of these points will be illustrated using an example involving predatory pricing and the familiar rationality constraint (also referred to as the need to demonstrate the plausibility of recoupment).

\section{Market Definition, Market Share, and Market Power}

Market power is important for most competition law offenses. It is central in assessing horizontal mergers, constitutes the first of two required elements for abuse of dominance (EU) or monopolization (U.S.), and also is significant with regard to many horizontal arrangements such as joint ventures. Market power fails to play a central role only with regard to price fixing and related practices, and, in some jurisdictions, certain other contractual arrangements. 
In this section, the focus is on the market definition / market share / market power paradigm, wherein one begins by defining a so-called relevant market and then examines the firm's (or firms') market share(s) in that market for the purpose of making an inference about market power. This methodology is embodied in many government guidelines (notably, for horizontal mergers), and in competition law practice it constitutes is the primary means of assessing market power. This is so despite widely acknowledged limitations of the market definition (MD) approach: the arbitrariness of defining markets, which requires line-drawing that entails all-or-nothing choices, and the challenge of inferring market power from market shares (MS's) even in a properly defined market. Nevertheless, the approach is endorsed and employed because it is regarded to be helpful, and the data needed to implement direct econometric alternatives, such as merger simulations, is often insufficient.

The use of imperfect proxies is familiar and can be helpful, but the practice does entail certain minimal demands if it is to make sense. In our context, it is necessary that there be a coherent way to infer market power from MS's in redefined (non-homogeneous goods) markets, but such does not exist. And there must be a means of determining which MD is superior in terms of providing the best (or least bad) inference of market power, but there is not. After articulating the logic behind these two claims, the uselessness and counterproductivity of MD is illustrated through the simplest and most standard applications to horizontal mergers, where MD has received the most attention and refinement. A final subsection elaborates the common yet puzzling practice of stating market power requirements as MS threshold tests, which will be shown to be incoherent as a matter of empirics and policy. ${ }^{1}$

\subsection{Inferring market power from market shares}

As stated, the MD paradigm is one in which market power is inferred from MS's in the relevant market. To assess how this inference may be possible, we need to begin with a definition of market power. For concreteness and familiarity, this subsection will consider the Lerner index that indicates the percentage of the price $(P)$ that is in excess of marginal cost $(M C)$, taken as a competitive benchmark:

$$
\Lambda=\frac{P-M C}{P} \text {. }
$$

In examining this expression, we can ask: Where is MD? Where is MS? Put another way, in order to use MD to ascertain MS for purposes of inferring $\Lambda$, we need a formula that relates these terms. There are two standard settings in which such a formula exists. Here, we will consider the case of a dominant firm with a competitive fringe that together supply the entire market for a homogeneous good. (The other standard case is presented in subsection 2.3.) In this case, following Stigler (1940),

$$
\Lambda=\frac{P-M C}{P}=\frac{1}{\left|\varepsilon_{f}\right|}=\frac{S}{\left|\varepsilon_{d}\right|+(1-S) \varepsilon_{r}} .
$$

In this formula, the dominant firm's elasticity of demand is $\varepsilon_{f}=(d Q / d P)(P / Q)$, where $Q$ denotes the quantity of the firm's output; the market elasticity of demand is $\varepsilon_{d}=(d X / d P)(P / X)$, where $X$ denotes total market demand; and the rivals' collective elasticity of supply is $\varepsilon_{r}=(d Y / d P)(P / Y)$, where $Y$ denotes rivals' total supply. Finally, $S$ is the dominant firm's market share, and hence $1-S$ indicates rivals’ aggregate share.

\footnotetext{
${ }^{1}$ The present analysis draws on and recasts Kaplow (2010, 2011a, 2011b).
} 
Two observations are in order. First, this formula (and the other introduced in subsection 2.3) is only valid for a homogeneous goods market. So, if we start in such a market, we have a means of inferring market power from MS. Otherwise, we do not (on which, more in a moment).

Second, this formula works: If the stated model applies, the formula allows us to translate the dominant firm's MS $(S)$ into an inference about market power $(\Lambda)$. Moreover, this is so regardless of the number of substitutes and how close of a substitute each one is - all without any need for even thinking about market redefinition. As is familiar, the market elasticity of demand, in the denominator of the rightmost expression, equals one plus the revenue-share-weighted sum of all the cross-elasticities of demand and hence incorporates the influence of all substitutes, each appropriately weighted. Supply substitution is similarly captured by the fringe firms' supply elasticity.

Because our formula works without the need to redefine markets, the MD paradigm is unnecessary here. Nevertheless, the paradigm insists on choosing the relevant market, readily contemplating that we might need to expand it by adding in substitutes. Suppose, then, that we do so. In that event, we need a new formula, one that works in our now non-homogeneousgoods market. Yet, for over a half century of economists redefining markets for the purpose of inferring market power from the shares therein, the literature does not contain a formula for making this inference.

This challenge is explored in Kaplow (2010), where it is suggested that we must have had in mind something like the following:

$$
\Lambda=\frac{P-M C}{P}=\frac{1}{\left|\varepsilon_{f}\right|}=\frac{\hat{S}}{\left|\hat{\varepsilon}_{d}\right|+(1-\hat{S}) \hat{\varepsilon}_{r}} .
$$

The term $\hat{S}$ refers to our dominant firm's share in the broader market. But it is less obvious what the two revised elasticities mean. They are implicitly understood to indicate some elasticity-like notions in the broader market, such as in Landes and Posner's (1981) discussion. But the actual meaning is obscure, for we no longer have a firm selling a homogeneous good subject to a competitive fringe, and the demand and supply notions in our now-variegated market could be viewed in multiple ways, none of which obviously answer our market power question. There exists a unique way of defining these modified elasticities that yields a valid answer:

$$
\begin{aligned}
& \hat{\varepsilon}_{d}=\frac{\hat{S}}{S} \varepsilon_{d}, \\
& \hat{\varepsilon}_{r}=\frac{(1-S) \hat{S}}{(1-\hat{S}) S} \varepsilon_{r} .
\end{aligned}
$$

These definitions work. But they work precisely because they undo the market redefinition. That is, no information whatsoever is utilized about demand or other rivals' supply in the market for the substitutes that were incorporated when redefining the market. As with our original formula, demand substitution continues to enter only through the demand elasticity in the original market, which is to say, only through the cross-elasticities of demand and the revenue shares that are implicit in the market demand in our original homogeneous goods market. This means that no information on the market elasticity of demand for our substitute products or no overall market elasticity in some composite market is employed. And this is precisely why this reversal of our market redefinition works. (To test this intuition, consider the simple, special 
case in which $\varepsilon_{r}=0$. If, say, our market redefinition halves our dominant firm's original market share, it is obvious that we must also deem $\hat{\varepsilon}_{d}$ to be half as high to obtain the correct answer, and this latter halving we know merely from the reduction in the dominant firm's share, without making use of any other information about the expanded market.)

In sum, economists, competition agencies, and courts have been purporting to redefine markets and then to make inferences from MS's in such redefined markets. This process has often been recognized to be somewhat loose, but when we examine its foundations, we see that none exist or can be constructed, short of reversing any market redefinition.

\subsection{Choosing the best market}

For this subsection, let us set to the side the problem of inferring market power from MS's in non-homogeneous goods markets and suppose that some market power inference can indeed be made. We will now consider the familiar question of MD, which presumably is meant to involve choosing the best market in some sense. Remarkably, virtually nothing is written stating what is thought to be the criterion for the best market, which in itself poses a challenge for MD. ${ }^{2}$ For present purposes, the best market will be taken to be that which is thought to result in the most accurate market power inference, based on the available information.

To make this principle operational, suppose that we are choosing between two markets: the narrower $(N)$ market is one in which our market power inference from a high MS will overstate market power, and the broader $(B)$ market is one in which our market power inference from a low MS will understate market power; the truth (as best we can tell) lies somewhere in between. Let $M P^{N}$ and $M P^{B}$ denote the market power inferences we would make conditional on choosing $N$ and $B$, respectively. Furthermore, let $\xi^{N}$ and $\xi^{B}$ be the errors associated with each choice:

$$
\xi^{i} \equiv\left|M P^{i}-M P^{*}\right|
$$

where $M P^{*}$ is our best estimate (or guesstimate) of market power in light of whatever information is available when the MD choice is being made. Our rule is to choose $i \in\{N, B\}$ according to $\min \left(\xi^{N}, \xi^{B}\right)$. That is, choose $i=N$ if and only if $\xi^{N}<\xi^{B}$. Accordingly, our market power inference is $M P^{N}$ if $i=N$ and $M P^{B}$ if $i=B$.

Having stated the simple logic of the MD process, its logical defects are immediate. First, the exercise is pointless. We need $M P^{*}$, our best estimate of market power given available information, as an input to the decision. Specifically, $M P^{*}$ was needed to define the errors ( $\xi^{N}$ and $\xi^{B}$ ) in order to know which one was lower. But once we formulate our best estimate, $M P^{*}$, however good or bad it may be, every subsequent step is wasted effort. (This, conveniently, includes the need to make inferences of market power in redefined markets, which subsection 2.1 shows to be impossible.)

\footnotetext{
${ }^{2}$ It is perhaps for this reason that the HMT was devised, but aside from the actual mechanics of the mechanism, it is never stated what is the criterion or maximand under which this choice is to be regarded as optimal or even a sensible proxy. As we will see in the next subsection, this apparatus is actually less effective than the more natural method examined here that itself constitutes a dominated strategy.

${ }^{3}$ A symmetric, linear loss function is employed for concreteness and is without loss of generality for purposes of the present argument.
} 
But the MD paradigm is worse. Our final estimate of market power is $M P^{N}$ or $M P^{B}$, as the case may be, which means that our additional effort is rewarded by our consciously making an avoidable error of $\xi^{N}$ or $\xi^{B}$. To be sure, we make the smaller of these errors - the lesser of two evils - but why do we wish to introduce even the lesser error, relative to $M P^{*}$, rather than just sticking with $M P^{*}$ ? Moreover, it is clear that this needless error can result in mistaken legal decisions, such as when $M P^{*}$ is sufficiently high that it is optimal to assign liability but we chose $M P^{B}$, which happens to be low enough to exonerate the firm. Likewise, choosing $M P^{N}$ can result in the mistaken assessment of liability.

The solution is to abandon the MD process. Or, if we must - perhaps because some authoritative legal source requires MD - we can eliminate this error by working backwards: first determine the correct outcome using $M P^{*}$, and then choose whichever of $N$ or $B$ rationalizes that choice. This does make MD a patently circular task, but at least it eliminates the avoidable error.

In closing, it should be noted that this argument, like that in the preceding subsection about the inability to make valid market power inferences from MS's in redefined markets, is a matter of definitions and deduction. It does not depend on what information is available, what stage we are at in the process (preliminary investigation versus final decision), or how good our best estimate, $M P^{*}$, actually is. If we have significant uncertainty about $M P^{*}$, as we often do, substituting another measurement that, from that baseline, introduces additional error - in essence throwing way or blurring some of our initial information - can only worsen the problem. ${ }^{4}$

\subsection{Application to horizontal mergers}

The analysis in subsections 2.1 and 2.2 indicates that the MD paradigm, in which markets are often redefined for purposes of making market power inferences from MS's in the relevant market, is subject to two logical defects, each of which is sufficient to undermine the enterprise. And subsection 2.2 further explains that insistence on this methodology can result in inferior legal outcomes. It is useful to illuminate these abstract, logical arguments by considering a concrete context. The one most favorable to the MD paradigm should be horizontal mergers, where the technique is most often employed and where guidelines articulating the MD approach are most developed. ${ }^{5}$ This subsection considers each of the three basic settings ordinarily examined, for if MD cannot handle the simplest and most standard cases, there is little hope that it can tackle more complex and subtle ones.

The merger guidelines' methodology for market definition uses the hypothetical monopolist test (HMT). Under it, one begins with the homogeneous goods market and asks whether a hypothetical monopolist in that market could profitably undertake a "small but significant and non-transitory increase in price” (SSNIP), say, five percent, above the current level. If so, that is the relevant market. If not, one adds the next group of substitutes and asks

\footnotetext{
${ }^{4}$ The present analysis indicates that direct estimation of market power is the only correct way to proceed, but it does not imply that the best way to make this estimate is to employ econometric tools regardless of the stage of the proceeding or quality of the data, or that when such methods can be used that they should be automatically privileged over other sources of information, such as internal documents, views of sophisticated buyers, and so forth.

${ }^{5}$ See, for example, U.S. Horizontal Merger Guidelines (2010), EU Guidelines on the Assessment of Horizontal Mergers (2004), EU Commission Notice on the Definition of Relevant Market (1997), and EU DG Competition Discussion Paper (2005).
} 
whether a hypothetical monopolist in that broader, redefined market could profitably elevate price five percent. If so, that is the relevant market. If not, one continues until the test is satisfied. Once the relevant market is defined, merger guidelines typically examine the postmerger $\mathrm{HHI}$ in the resulting market as well as the increment to the HHI due to the merger in order to determine safe harbors, ranges of likely challenge, and so forth. For example, under the U.S. Horizontal Merger Guidelines (2010), a merger that raises the HHI by more than 200 points and results in an HHI above 2500 is presumed to be likely to enhance market power sufficiently to warrant a challenge.

A few preliminary observations are in order. First, it seems odd that a hypothetical monopolist test is used in examining mergers (that are not ordinarily to monopoly). Second, despite all the mechanics, no mention is made of how much price elevation is thought to be sufficient to trigger a challenge. This relates to a third point, that the measures are all in terms of HHIs (a transposition of MS's) and not in terms of market power, a feature that will be explored further in subsection 2.4 .

To begin, consider the unilateral price elevation effects of a merger of firms that sell homogeneous goods in a market wherein interactions are Cournot (quantity-setting). It turns out that this is the second main context (in addition to that with a dominant firm, examined in subsection 2.1) in which there is a formula that translates MS's (specifically, the HHI) into price elevation. This formula indicates that the industry-wide average, output-weighted margin equals $\mathrm{HHI} /\left|\varepsilon_{d}\right|$. Using this formula, inserting the post- and premerger HHIs, and then taking the difference, we have a basis for determining the price elevation caused by the merger (setting to the side the important qualifications in Farrell and Shapiro (1990) that are not central for present purposes). In other words, no HMT or other mode of MD is required to handle this case. However, if we were to redefine the market, as the HMT may require, we then would no longer have a homogeneous goods market and our formula would be useless: its derivation (like that of our earlier formula for a dominant firm) presumes that the market has homogeneous goods. And, as before, there is no valid formula for the broadened market (short of reversing the redefinition). Therefore, the HMT approach, whenever it redefines the market, forces us to abandon a setting in which we can answer our price elevation question and enter a realm with no guidance.

For unilateral effects with differentiated products, the HMT fares no better. It is now familiar from the literature on critical loss and upward pricing pressure (setting various disputes to the side) that the core information required to analyze a merger between two firms that each sell a differentiated product is the markup on each product and the diversion ratio between the two. ${ }^{6}$ MD has nothing to do with this: The answer is the same whether the HMT defines a market with three or thirty-three other goods, and no analysis particular to any such relevant market illuminates our question of the price effects of the merger. ${ }^{7}$

Finally, consider coordinated effects: the prospect that a merger will facilitate collusion in some form. Here, the expected price effects are a product of two factors: how much the merger facilitates coordination, and how much price would be elevated if coordination were

\footnotetext{
${ }^{6}$ See, for example, Baker and Bresnahan (1985), Harris and Simons (1989), and Farrell and Shapiro (2010).

${ }^{7}$ As a formal matter, one could define the market as consisting of only the two merging firms' products, apply the first round of the HMT, and stop (regardless of the SSNIP requirement), using the intermediate output as the final answer. After all, the HMT asks how much a hypothetical monopolist of the stated market can profitably elevate price, and the merged firm will be an actual monopolist of the "market" consisting of (only) the two products it sells.
} 
successful. MD purports to be relevant to the latter question, but it is not. ${ }^{8}$ Typically, coordination is imagined to take place - if it does at all - among sellers of homogeneous goods (or those that are nearly so), a theoretical conjecture that is substantially borne out by evidence from prosecuted cartel cases that most often involve firms that sell homogeneous intermediate goods. In this standard coordinated effects case, the HMT is correct if, after the first step, one stops regardless of whether it is satisfied. That is, we begin with the homogeneous goods market and ask how much a hypothetical monopolist (which is what a perfect cartel would mimic) can raise price in that market. This is our answer, full stop. If it happens to be less than five percent, ten percent, or some other target, there is no point in redefining our market by adding various substitutes and asking how much a hypothetical monopolist of that market could raise price, because that is not our relevant group of firms. In essence, we would have defined an irrelevant market. In summary, in all three of the standard settings, the sequential HMT approach, and MD more generally, is not merely unhelpful but consistently counterproductive.

It is also true that merger guidelines' mixture of the HMT and the various HHI thresholds is highly problematic in ways that are unappreciated. ${ }^{9}$ This point can be seen by using our formula for unilateral price elevation in a homogeneous goods market. Consider a case that just enters the above-mentioned danger zone under the U.S. Horizontal Merger Guidelines (2010): the merger raises the HHI from 2300 to 2501, and suppose that the HMT is barely satisfied for the homogeneous goods market, which is to say that a hypothetical monopolist of it would elevate price barely over $5 \%$. In other words, this merger is presumptively subject to challenge. Simple calculations yield the following: $\left|\varepsilon_{d}\right| \approx 16$, the premerger price elevation is approximately $1.42 \%$, and the postmerger elevation is approximately $1.55 \%$. That is, this presumptively illegal merger elevates price by a mere $0.13 \%$.

Contrast a second case, a merger to monopoly, that in fact would raise price $4.9 \%$ in our homogeneous goods market. Because this means that round one of the HMT fails, we are commanded to broaden the market. Suppose, moreover, that the included substitutes involve competitive markets with total revenue that is ten times higher than that in the initial market, which will plunge the postmerger HHI and HHI delta below the safe harbor cutoff.

Finally, juxtapose these two cases: In the first, we presumptively challenge a merger that raises price by $0.13 \%$, and, in the second, we safe harbor one that raises price by $4.9 \%$. That is, we not only get the ordering backwards, but we do so in a pair of cases where the price effects differ by more than thirty-five fold. It is remarkable that, in the simplest of cases - no complications due to supply substitution, entry, merger-specific efficiencies, and so forth - the HMT/SSNIP approach that has been standard for decades misfires so badly. This illustration, along with the discussion of the three basic settings, indicates that the abstract logical arguments of subsections 2.1 and 2.2 have powerful practical implications for the conduct of competition policy.

\footnotetext{
${ }^{8}$ It may also be thought relevant to the former question because having fewer firms is more conducive to coordination, but the argument to follow in the text applies here as well: What matters are the firms that might be expected to coordinate, not firms selling other products that would continue to behave independently.

${ }^{9}$ It will be apparent after reading subsection 2.4 that the example here will illustrate the ideas from all the subsections in section 2 .
} 


\subsection{Market share threshold tests}

Although market power is taken to be a central element of many legal rules in the competition policy domain, it is standard to denominate these requirements as market share threshold tests. The running example for this subsection will be abuse of dominance (equivalently, monopolization), where we will suppose that the market power requirement is presumptively met by a MS of at least 50\%. (Similarly, as just discussed in subsection 2.3, merger guidelines state market power targets using HHIs, which are a transformation of MS's.) It should be apparent from the outset that this practice is problematic because of the uncertainty and variety of market power implications that can be associated with a given MS, even in a properly defined market. As we now shall see, the difficulties run deeper.

Reliance on MS's conflates two distinct questions. The first is empirical: How much market power is thought to be implied in fact by a stated MS threshold, say, our $50 \%$ for dominance? The second question is one of policy: How much market power should be required as a matter of sound competition policy with regard to the practice under consideration? Because these are entirely separate questions, how can a single number - a MS threshold answer both of them simultaneously? The matter is actually worse, because MS's cannot answer either question since both are denominated in market power whereas MS is not.

Begin with empirical assessment, and let us consider the Lerner index: $\Lambda=(P-M C) / P$. For the case of a dominant firm with a competitive fringe in a homogeneous goods market, we discussed how MS is related to market power. But it remains true that MS is only one factor; specifically, the elasticity of market demand and of rivals' supply matter as well, so even granting that we are considering a properly defined market, a given MS can be associated with a very wide range of levels of market power, and conversely.

Hence, MS cannot be a proper answer to any sort of empirical market power question. Indeed, it is not even in the right units. It is as if, in answering the question of how heavy a package is, someone answered " 0.2 cubic meters." All else equal, volume is positively correlated to mass, but if we heard such an answer in a setting in which the density was unknown and could vary widely, we would think that the respondent was very confused or, at a minimum, did not understand the language. Yet competition policy discourse has been answering market power questions - both empirical and policy-oriented - in the language of MS's from the beginning.

Regarding legal policy, the problem can be illustrated in many ways. Consider a legal standard that indeed states a presumptive MS threshold of 50\%. How much price elevation do we imagine is contemplated? $2 \%$ ? 22\%? $72 \%$ ? Or, running in the opposite direction, suppose that a legal policy judgment is made that a certain unilateral practice should give rise to liability only when the dominant firm employing it is able to elevate price at least $20 \%$. What, then, is our implicit MS threshold? 28\%? 88\%? If a weight limit for a bridge or an elevator were specified in cubic meters, the matter would be regarded to be laughable.

To develop the problems that can arise in routine cases, suppose that in a dominance challenge the defendant firm argues that, even though the presumptive threshold is a MS of 50\% and its own MS is 60\%, its share in this particular market implies a sufficiently low level of market power that the threshold should be deemed not to be satisfied. Moreover, suppose that none of the relevant facts in the case is disputed. How can we resolve the matter? ${ }^{10}$

\footnotetext{
${ }^{10}$ For further development of this idea as applied to Judge Hand's famous pronouncement in Alcoa of the market share threshold for the monopolization offense, see Kaplow (2011b).
} 
First, to know whether the defendant's argument is worth listening to, we would need to know how much market power is ordinarily implied by a MS of 60\%; after all, the defendant's claim is that market power in this case is less than is ordinarily conveyed by that share. But how much market power is ordinarily conveyed by a share of $60 \%$ ? What would we consult to find out? Furthermore, if we could answer this question and also establish that the relevant facts of the case indeed meant that market power was lower than this figure, we would still need to know if that level of market power was below that implicitly conveyed by the $50 \%$ presumptive MS threshold. But we do not know that amount either. We might also ask, on the market power rather than the MS side of the ledger, whether any of our facts imply that we should be requiring more or less market power than the presumptive level in light of the practice and particular market circumstances (on which, see section 3), but there is no presumptive market power level indicated by our 50\% MS threshold in the first place. Taken together, because our legal test and the facts of the case at hand are both denominated in terms of MS, whereas both need to be answered in terms of market power, we are left at sea. Even if the facts were uncontested, we do not know even the direction in which to adjust our inferences from the $60 \%$ market share, much less the magnitude of any requisite adjustment. This predicament is peculiar in light of the fact that competition agencies, courts, and private parties, often guided by economists, have purported to answer questions of this sort in countless cases for over half a century.

This mismatch can also be seen from another angle. Suppose that in a contested monopolization case - imagine litigation in the U.S. court system - each side is required to submit its expert report on market power simultaneously, and both, it so happens, report that the Lerner index is 0.136. Who wins on the market power question? Because the market power threshold is, let us continue to suppose, a MS of 50\%, there is no way to know. It may be agreed that in the narrower market the defendant's share is $80 \%$ and in the broader market $20 \%$, and be disputed which MD is correct. Yet, recall, both sides agree precisely on market power (to three significant digits, no less). That is, we wish to know whether market power is sufficiently high, both parties agree on its exact level, but we have no idea what outcome follows. In the United States, for example, no answer can be found in various guidelines, court opinions, legal treatises, or other sources. All state that there is a market power requirement, and all denominate it in terms of MS.

The implication of this analysis is that any market power requirements should be denominated in market power terms (not MS) and inquiries into market power in individual cases should likewise aim to measure market power (not MS). Note, moreover, that there is a perverse synergy between the problem examined in this subsection, the use of MS in place of market power, and the focus in earlier subsections on MD: When legal tests are denominated in terms of MS rather than market power, MD seems to be a necessity. However, if it is accepted that market power - not MS standing alone - is the question, then any need to engage in MD can be viewed entirely pragmatically, so that once its logical defects are appreciated, the methodology can appropriately be discarded.

\section{The Role of Market Power in Competition Policy}

This section draws on a larger work in progress. It focuses first on the articulation of unappreciated assumptions in existing understanding about the role of market power, some of which indicate significant infirmities in how challenged practices are assessed. Second, it sketches a ground-up analysis of the channels through which market power in various guises 
may be relevant to optimal decisions about liability, all the while identifying gaps in existing theory and empirical knowledge that currently pose obstacles to the effective operation of competition regimes.

As background, it is useful to state the legal relevance of market power under competition law. For concreteness, consider allegedly exclusionary behavior by a powerful firm. In the European Union, Article 102 TEFU states two requirements: that the firm has a "dominant position” and that it engaged in "abuse." Similarly, in the United States, Section 2 of the Sherman Act requires that the firm has "monopoly power" and committed an exclusionary act to create, augment, or maintain that power. These and other canonical statements are reflected in competition agency guidance documents that likewise comprehend the test as involving two distinct elements, each of which must be met separately. ${ }^{11}$

The next two subsections make explicit what such an approach entails. That is, the familiar prose is translated into simple mathematics, which provides a clear view of what these formulations actually mean and what implicit assumptions they involve. It is suggested that industrial organization economists, including those serving in competition agencies or as expert witnesses, do not really believe what is routinely stated and, we would hope, in practice deviate substantially from existing rules' dictates. Nevertheless, doing the work of competition regulation or conducting research under false yet fairly uncontroversial rubrics is unconducive to quality decision-making and to the advance of knowledge.

Furthermore, we need to figure out and articulate what we should be doing on these

fronts. The third subsection identifies the main channels by which market power might be relevant. As will be seen, a further central consideration is that the appropriate meaning or sense of market power can differ across and within channels. ${ }^{12}$ The fourth subsection briefly illustrates a handful of these fairly abstract points by examining the familiar individual rationality constraint (also known as the recoupment requirement) for predatory pricing. The preliminary exploration offered here turns out to fortify some existing beliefs, map uncharted territory, and affirmatively disrupt some standard views (notably, by suggesting respects in which greater market power can weaken the case for liability). These constructive portions of this section are, in the end, the most important, but they are also the least complete, suggesting the need for additional work.

\section{1. $f(M P, A)>k *$}

This simple inequality is meant to depict the familiar notion that whether to assign liability depends on the magnitude of market power and the strength of evidence indicating the anticompetitive nature of the act under scrutiny. In the expression $f(M P, A)>k^{*}, M P$ is the measure of the degree of market power and $A$ of the strength of indication that the act is abusive or exclusionary in the relevant sense. The function $f$ is a mapping of these two variables to the

\footnotetext{
${ }^{11}$ See, for example, EU DG Competition Discussion Paper (2005) and U.S. Department of Justice (2008) (which was withdrawn in 2009 due to disagreements about other matters).

${ }^{12}$ Reflection on this conclusion further suggests the futility of the MD paradigm, beyond the criticisms in section 2. If, as turns out to be the case, market power is relevant in different senses and through different channels in different settings, it is even more difficult to render coherent an exercise that attempts to offer a common template for defining "the" relevant market. It is also true (although space does not permit elaboration of examples here) that market share can have significance in various ways, but the "relevant market" for examining the share may have little to do with either familiar or more novel MD rubrics that are aimed at market power assessment.
} 
real line, with higher values indicating a stronger case for liability and $k^{*}$ being the critical value above which assignment of liability is optimal. For the moment, the only further properties that will be imposed are $d f(M P, A) / d M P>0$ and $d f(M P, A) / d A>0$.

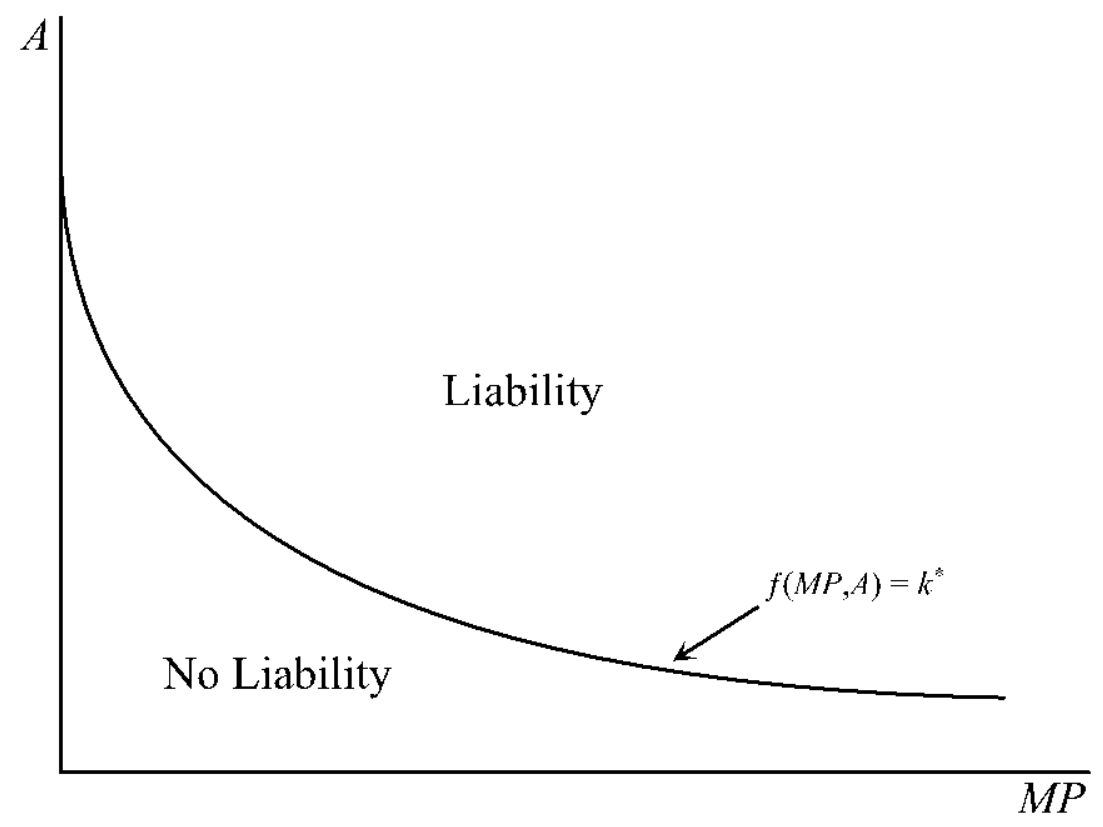

Figure 1

A possible representation of this function appears in Figure 1. Given our assumptions and the way this figure is drawn, the following features may be noted. First, greater market power and stronger evidence that the act is anticompetitive each favor liability. The strictly positive derivatives of $f$ with respect to each of $M P$ and $A$ (and hence the downward sloping curve in Figure 1) indicate some willingness to trade off between the two. For example, if evidence that the act is truly abusive is stronger ( $A$ is higher), then market power (MP) need not be as high in order for liability to be assigned. In addition, this particular representation indicates that very strong evidence on the act (a very high $A$ ) is sufficient for liability (perhaps blowing up a competitor's plant). On the other hand, even if $M P$ is extremely high, there is no liability unless evidence on $A$ is of at least moderate strength. This latter point necessarily holds unless there is a regime of "no-fault monopolization" under which sufficiently powerful firms are broken up or subject to sanctions regardless of how they have behaved.

Two further observations are in order. First, once this simple relationship is stated concretely, we immediately appreciate that we in fact know almost nothing about the optimal shape or height of this curve - that is, about the functional form for $f$ or, for a given calibration thereof, the optimal value of $k^{*}$. 


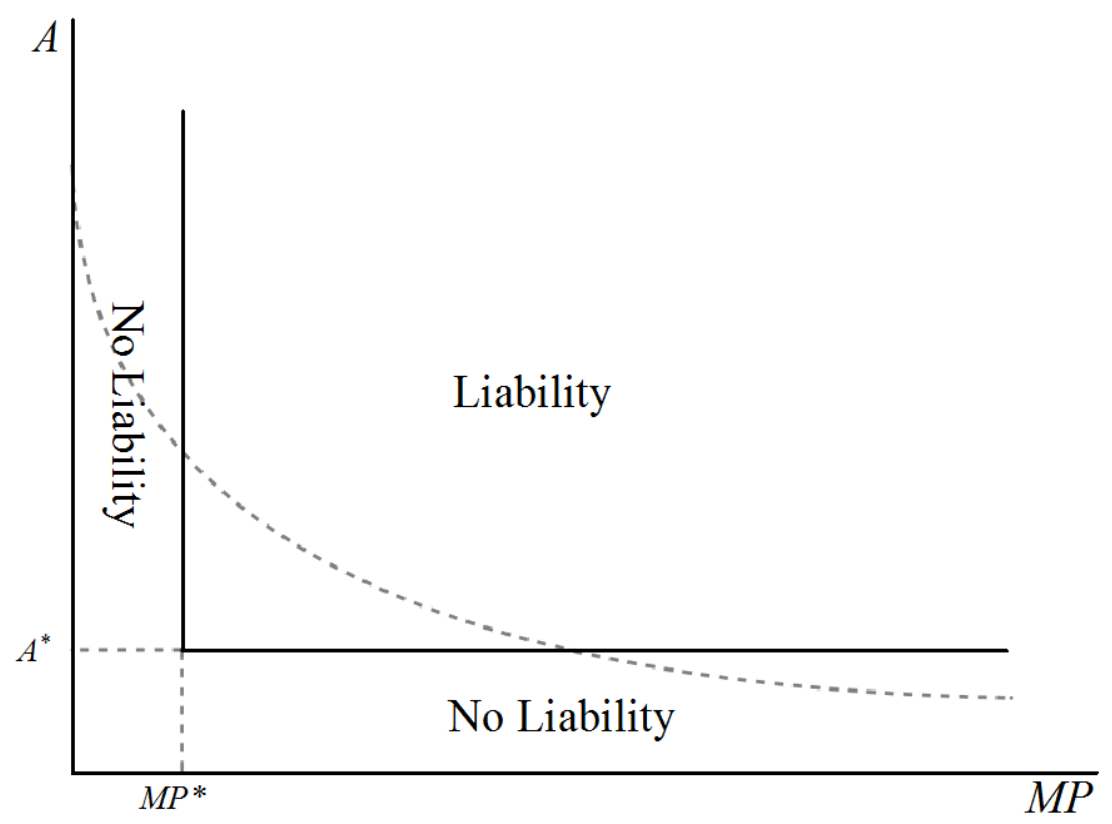

\section{Figure 2}

Second, this simple, intuitive function and Figure 1 do not properly depict the official, two-element view of liability. Rather, the canonical rule entails the "L" shaped curve in Figure 2. That is, the two-element approach corresponds to a lexicographic functional form for $f(M P, A)$ wherein liability is assigned if and only if

$$
\begin{aligned}
& M P>M P^{*} \text { and } \\
& A>A^{*} .
\end{aligned}
$$

It seems a priori implausible as a matter of economics and under any sensible welfare criterion that the optimal mapping from $M P$ and $A$ to liability would be lexicographic. This functional form indicates, for example, that there must be some (generally regarded to be substantial) level of $M P$, at least $M P^{*}$, for liability to attach when, say, $A$ is barely above $A^{*}$, but when $A$ is very much in excess of $A^{*}$, we would not tolerate assigning liability if $M P$ were smaller by a trivial amount. ${ }^{13}$

Although the rule of liability is most often stated in this lexicographic fashion and not much criticized on this account, we might suppose that agencies and courts do not in fact behave in accord with the formal rule but instead contemplate tradeoffs regarding $M P$ and $A$. It is interesting to note in this regard the points in subsection 2.4 that market power thresholds (in the present notation, $M P^{*}$ ) are stated pretty much exclusively in terms of MS's rather than market power and, moreover, that any given MS (say, 50\%) can, even in basic settings, be associated with just about any level of market power. Therefore, what is formally required, even if taken as a fixed, lexicographic, legal hurdle, is denominated in a manner (MS rather than market power)

\footnotetext{
${ }^{13}$ A market power threshold test requiring that $M P>M P^{*}$ might be favored for reasons of predictability in guiding business decisions. However, because market power must be quantified in a given case (unlike some dichotomous classifications involving qualitatively distinct things) and it is difficult to predict how an agency or court will quantify it, the value of a sharp test for this purpose is diminished. Moreover, the analysis to follow suggests that the appropriate market power requirement, when one makes sense, depends significantly on the particular act under scrutiny, so a one-size-fits-all rule is problematic.
} 
that gives essentially an infinite degree of freedom in application. Hence, because the legal tests with regard to market power actually say nothing at all, we perhaps need not be worried that they bind competition practice in ways that make no sense. Of course, it is not a satisfactory state of affairs if this maneuver (itself not broadly appreciated) is the best answer competition law has to offer in order to avoid its prima facie nonsensical legal requirement.

Setting aside this lexicographic functional form, let us now return to the more plausible version of $f(M P, A)$ depicted in Figure 1, wherein the derivatives with respect to each of $M P$ and $A$ are taken to be strictly positive. As will now be discussed, this seemingly more appealing and fairly general statement is still restrictive in other respects that are problematic.

\subsection{Looking behind $f(M P, A)$}

Subsection 3.1 articulates the functional relationship that is implicit in standard articulations of inquiries into market power for the purposes of deciding whether to assign liability. In this subsection, we will begin at the beginning. In any given case, there is some vector of evidence $e$. This vector may be mapped to a real number that indicates case strength and, in particular, whether the evidence as a whole is sufficient to warrant liability, by the rule: $f(e)>k^{*}$. Our function $f$ is understood to be derived from a welfare function; it indicates the social cost of failing to assign liability.

Given the general formulation, $f(e)$, what is being said when we instead employ the reduced form $f(M P, A)$ ? To begin, let $e^{M P}$ and $e^{A}$ be two sub-vectors of $e$. Next, we will define $M P$ and $A$ in terms of two subfunctions from these sub-vectors:

$$
\begin{aligned}
& M P \equiv g^{M P}\left(e^{M P}\right) \\
& A \equiv g^{A}\left(e^{A}\right) .
\end{aligned}
$$

Now we can rewrite $f(M P, A)$ as:

$$
f(M P, A) \equiv f\left(g^{M P}\left(e^{M P}\right), g^{A}\left(e^{A}\right)\right) .
$$

Taken together, these expressions indicate how our original formulation, $f(M P, A)$, entails two separate evidence clusters, one about market power and the other about the act under examination; some functional mappings from each of these evidence clusters to respective intermediate conclusions, one about market power and the other about the act; and, finally, a further mapping from those two intermediate conclusions to a final indicator of the strength of the case for purposes of assigning liability.

Stated in this manner, we can see that this functional relationship entails a significant restriction relative to the more general form $f(e)$. Specifically, writing $f\left(g^{M P}\left(e^{M P}\right), g^{A}\left(e^{A}\right)\right)$ embodies a weak separability assumption regarding how our sub-vectors, $e^{M P}$ and $e^{A}$, influence liability. One implication is that the impact of varying a particular element of $e^{A}$ on the value of $f$, which determines our liability decision, must be the same for any sub-vector $e^{M P}$ that yields the same value of $M P$. And conversely regarding $e^{M P}$ for a given value of $A$.

This means, for example, that whether $M P$ is lower by some amount as a consequence of greater demand substitution or easier entry is irrelevant, as long as the impact on the level of market power is the same. Nor, for a given level of $M P$, does it matter whether our assessment arose in a homogeneous or differentiated products industry, from Cournot or Bertrand interaction, and so forth. Nor do the implications of any of these aspects of market power depend on the nature of the act we are considering as long as the subfunction $g^{A}\left(e^{A}\right)$ yields the 
same level of $A$. For example, the impact of a given level of market power is the same regardless of whether we are examining exclusive dealing or predatory pricing, whether the predation relates to sequential potential entrants in a given market or across markets, the information structure between predator and prey, and so on - again, as long as the value of $A$ (without regard to aspects of market power) is the same. Moreover, it is supposed that the impact of market power on whether to assign liability does not depend on which alternative, benign explanations might be offered for the activity in question.

Industrial organization economists, whether in the academy, competition agencies, or litigation consulting firms, do not believe this. Perhaps careful analysis of myriad permutations would identify subsets of activity in which weak separability is a good approximation; if so, we do not currently know what those subsets are or what functional relationship between $M P$ and $A$ governs in each of those domains. Yet this weak separability assumption is what is entailed in standard formulations that have been accepted for decades.

It is also worth reflecting more on our two sub-vectors, $e^{M P}$ and $e^{A}$. One might interpret them as involving a disjoint partition of the evidence vector $e$ : some of the relevant evidence pertains to market power and some to assessing whether acts are abusive, with no overlap. This feature also seems implausible. We can relax this restriction and allow elements of $e$ to be in either or both of $e^{M P}$ and $e^{A}$. The limit of this relaxation, however, essentially returns us to the general function $f(e)$. If, for example, we allow $e^{A}$ to be coincident with $e$, then $g^{A}\left(e^{A}\right)$ could just be the general function $f(e)$, and our supposedly restrictive function $f(M P, A)$ can simply be the identity function with respect to its second argument (thus being invariant with respect to the first argument, $M P$ ). At that point, there is no meaningful sense in which a separate inquiry into market power is being conducted.

Therefore, if the familiar formulation - the prose analogue to $f(M P, A)$ - is to have content, to offer guidance, or to serve as a useful heuristic even if not literally believed, some substantial separability is entailed. Where on the continuum from $f(M P, A)$, as usually understood, to $f(e)$, which is completely general, we should operate, is unstated.

It is useful to contemplate some intermediate cases, not so much to identify the truth of the matter (which varies across contexts and about which little is known) but to motivate further reflection. Specifically, suppose that we allow more than two subfunctions that our function $f$ then maps to a liability assessment. Again, there are limiting issues: If $e$ has $N$ elements, and we allow $N$ subfunctions, no restriction is entailed. But there is much ground in between.

For example, consider dividing market power further, as follows (the subfunctions and sub-vectors are omitted for convenience):

$$
f\left(M P^{1}, M P^{2}, A\right) \text {. }
$$

That is, market power might be viewed as having two dimensions: perhaps demand substitution and supply substitution; or perhaps the level of market power and the delta (change in market power), which may interact differently with an indicator of the overall strength of the act evidence; or perhaps demand substitution and market share, the latter having potential relevance in addition to its influence on the Lerner index because it may bear on the magnitude of foreclosure. Or consider another example:

$$
f\left(M P, A^{1}, A^{2}\right) \text {. }
$$

Perhaps (as developed in the next subsection) there is a harmful (abusive) type of act and a benign type, and different clusters of evidence bear on certain aspects of each. Or perhaps the two components concerning the act refer to costs and benefits of prohibition for a single type of 
act (like a horizontal merger), where market power may have a different interaction with each (higher market power may raise the benefit of prohibition but not affect the cost, if it involves forgoing some sort of production efficiencies).

These illustrations - which, in turn, are obviously suggestive of others that are more complex although still more restrictive than $f(e)$ - raise the possibility that intermediate formulations of the relationship between market power evidence $\left(e^{M P}\right)$ and act evidence $\left(e^{A}\right)$ might be useful in some settings. This subsection and the preceding one, however, operate at a high level of abstraction. Further progress requires that we turn our attention more directly to the substance of the matter at hand.

\subsection{Market power's relevance}

Agency statements and much competition policy literature emphasize the relevance, indeed, central importance, of market power to liability yet do little to elaborate the actual channels of influence. There are, to be sure, numerous arguments or connections made in the course of one or another specific analysis of individual practices, perhaps in a particular industry setting. But these inquiries are largely ad hoc, with little sense of the governing framework from which the particulars emerge. This subsection attempts to offer a more systematic exploration of what types of linkages may exist. This is an area in which, going forward, industrial organization economics research can add significant value to competition policy and practice.

Before we begin, however, it is useful to pose the question: Why don't we just look at each act in its particular context and determine as best we can whether it is net desirable or detrimental? That is, we might largely dispense with market power as a separate category of analysis and the implicit view that there is some sub-vector $e^{M P}$ that has particular, independent significance. Instead, we would simply regard all evidence as potentially relevant to the assessment of the act itself and proceed from there. Moreover, one could justify the ad hoc approach just described if in fact there was little that was systematically true about the relevance of market power.

It is widely believed, however, that there are some patterns. Given the a priori plausibility of regarding market power as significant in many competition inquiries and the longtime understanding to that effect, it is appropriate to consider more explicitly just how this may be so. If, in the end, there is little more than a long list of potential context-specific factors whose relevance varies significantly from one setting to another, then it would be appropriate to abandon routine, systematic inquiry into market power. This section presents a simple organizing scheme that generates suggestions of various avenues.

\subsubsection{Framework}

Allegedly anticompetitive acts are not best examined in a vacuum. Rather, our question is whether to assign liability, a problem in decision analysis or mechanism design. When examining the evidence in a particular case, the optimal decision depends inevitably on an assessment of the relative strengths of anticompetitive and procompetitive explanations. As a practical matter, this is what investigators and adjudicators are doing when they are deciding whether to pursue a matter or, after considering all the evidence, to prohibit a practice or proposed merger or to apply sanctions on account of a firm's prior activity. 
But the two types of explanation often are not sharply stated, and much discourse proceeds on the view that each is to be considered sequentially rather than comparatively. ${ }^{14}$ Notably, agency statements and court decisions, along with treatises and other competition policy literature, typically call for an initial determination of whether a challenged practice is anticompetitive. If and only if an affirmative decision is reached does one proceed to consider procompetitive justifications. ${ }^{15}$ This bifurcation, in which each assessment is siloed, interestingly parallels the aforementioned separation of market power assessments and the examination of evidence on acts themselves. Even apart from this article's focus on market power, such further siloing is often counterproductive. First, much evidence regards classification, that is, an assessment of relative likelihoods (see subsection 3.3.2, just below). Second, fixing the likelihoods of each explanation, whether possible anticompetitive effects should be deemed sufficiently worrisome depends on the consequences of mistaken assignment of liability, so one cannot set a sensible threshold for anticompetitive effects without regard to pertinent procompetitive effects.

To proceed, we will, like in the earlier subsections, be more explicit, which will facilitate our investigation of the possible roles of market power. Focus on the case in which there are only two competing explanations (although realistically there may be more, including the important possibility of a continuum along some dimensions). Suppose further that there is nontrivial uncertainty regarding which explanation is correct. Therefore, we face a familiar error tradeoff. Our question is how a better understanding of market power might improve the efficiency of our liability decision-making.

In our posited case, liability will be desirable according to a simple cost-benefit test, that is, when the expected gain exceeds the expected cost:

$$
p^{G}(e) G(e)>p^{L}(e) L(e) .
$$

In this expression, $p^{G}(e)$ and $p^{L}(e)$ are the probabilities that the act is of the anticompetitive and procompetitive type, respectively. $G(e)$ is the gain from liability conditional on the act being anticompetitive, and $L(e)$ is the loss from liability conditional on the act being procompetitive; each should be interpreted as the present value of expected consequences given the pertinent explanation being true. (It is also instructive to consider the special case of mutually exclusive and exhaustive explanations, in which event the test for liability is $p(e) G(e)>(1-p(e)) L(e)$, where $p(e)$ is the probability that the act is anticompetitive rather than procompetitive.)

In these formulations, our question is: Where is market power? The answer, as will be explored in the following three subsections, is that it must be (if it is indeed relevant) in one or more of our components, $p^{G}(e), p^{L}(e), G(e)$, and $L(e)$.

Before proceeding, two further notes are in order. First, it is worth reflecting on the latter two items, which are obviously relevant but too often neglected. That is, much discussion of

\footnotetext{
${ }^{14}$ Much academic economics work - for good reasons, but with limitations that are highlighted in the discussion that follows - takes as the competing hypothesis some sort of null. A model of exclusive dealing that forecloses entry may, for example, give conditions under which it is effective; if it is not, exclusive dealing would not arise in the model. But in an actual case involving a challenge to exclusive dealing, we may know that it exists but be uncertain about its effects, specifically, whether it is exclusionary or efficiency-enhancing. Likewise, empirical work often takes as the null hypothesis whether a coefficient is statistically significantly different from zero, whereas in a challenge to an alleged abusive act, we may wish to know the relative likelihood of two distinct explanations. Of course, some modeling and empirical work is explicitly comparative in ways that more directly illuminate optimal decision-making regarding challenged practices.

${ }^{15}$ See, for example, EU DG Competition Discussion Paper (2005) and U.S. Department of Justice (2008) (which was withdrawn in 2009 due to disagreements about other matters).
} 
optimal competition law decisions regarding liability focuses on something like truth in the case at hand: "Which outcome is right?" is understood as tantamount to "Which characterization of the practice is more probably correct?" But this view is erroneous. Just as in deciding on medical treatment, we need to know far more than whether the likelihood that the patient has an ailment exceeds fifty percent (or some other common threshold). We also need to know the net benefit if the treatment in question succeeds when one has the ailment and the net cost if it fails, including adverse side effects when the ailment was not really present. The optimal probability threshold can be far above or far below fifty percent. Therefore, it is important that assessment of the role of market power not be confined to the question of classification that often commands the most attention.

Second, the foregoing cost-benefit test, which will be the center of attention here, is the correct decision rule in only one of the two main types of settings with which competition policy and other types of regulation are concerned. This inequality depicts the appropriate formula for the case in which an act may be prohibited (liability) or permitted (no liability) going forward. Merger assessments or decisions whether to enjoin a particular practice would be central examples. The other setting involves the application of sanctions (such as for price fixing, but also for past abusive activity), the prospect of which deters anticompetitive behavior but also chills procompetitive activity. ${ }^{16}$ Recent work on the economics of enforcement more generally (Kaplow 2011c, 2011d, 2014) elaborates the differences and derives the optimal decision rule when the central concern is with ex ante incentives. It turns out that this rule is qualitatively different (corresponding to the difference between decision analysis and mechanism design). Nevertheless, the present discussion of the simpler rule is helpful: Regarding classification, what is relevant for ex ante incentives rather than for prospective dictates is not the Bayesian posterior probability (derived - for concreteness, in the case of two mutually exclusive possibilities - from the prior probability and the likelihood ratio associated with the evidence) but just the likelihood ratio, so references in such instances to $p^{G}(e)$ and $p^{L}(e)$ can be reinterpreted accordingly. And the factors pertaining to deterrence gains and chilling losses (both involving ex ante behavior that is endogenous in the analysis) are much more involved, but some aspects are similar enough in spirit that the discussions here of $G(e)$ and $L(e)$ - which will be fairly loose in any event - are suggestive.

\subsubsection{Likelihoods: $p^{G}(e)$ and $p^{L}(e)$}

In attempting to assess whether a challenged practice should give rise to liability, most attention is devoted to whether the act has anticompetitive or procompetitive effects. In so doing - and, for convenience of exposition, briefly considering the case of mutually exclusive acts ${ }^{17}{ }_{-}$ evidence only favors classification as an abuse if an anticompetitive act is more likely to generate it than is a procompetitive one, which is to say, if the associated likelihood ratio exceeds one. If the likelihood ratio is below one, the evidence moves the assessment toward the act being procompetitive. In both the search for relevant evidence (investigation) and the assessment of it

\footnotetext{
${ }^{16}$ In reality, the cases overlap - an abusive practice may be subject to sanctions and also be enjoined going forward - in which event the optimal decision rule is a blend of that for the two pure cases.

${ }^{17}$ For explanations that may not be mutually exclusive, evidence on the two probabilities (that is, holding $G(e)$ and $L(e)$ constant) favors liability if it raises $p^{G} / p^{L}$, as can be seen from a simple rearrangement of the aforementioned cost-benefit test. Hence, the question is not whether evidence (such as that indicating greater market power) raises $p^{G}$ by more than it raises $p^{L}$ in absolute terms, but whether it raises the former by relatively more than it raises the latter (including, as will be discussed, the important cases in which greater MP does not raise or even lowers $p^{L}$ ).
} 
(decision-making), one must engage in a comparative process. (Put sharply, one cannot assess a likelihood ratio without regard to its denominator.)

Our specific question is how evidence on market power, $e^{M P}$, is relevant to this endeavor. A commonly supposed case - which seems apt in many settings, but not all - is that the anticompetitive strategy would be profit-maximizing only if there is a nontrivial level of market power, whereas the plausibility of the procompetitive explanation is independent of the level of market power. (For example, market power may be necessary for tying to be exclusionary but not for a physical tie to reduce production or distribution costs.) If so, then $p^{G}(e)$ is rising in market power but $p^{L}(e)$ is not. We might imagine the pure case, in which there is a threshold level of market power at which the anticompetitive strategy becomes profitable, in which event $p^{G}(e)$ would be invariant to market power except for an upward jump at that point. More realistically, given imperfect information within the firm, imperfect observability by the adjudicator, and a host of other considerations, we may expect $p^{G}(e)$ to rise barely at all when market power is trivial, then ever faster as the estimated break-even point is passed, and then at an ever slower rate thereafter.

Note further that this illustration suggests concrete answers to some of the lingering questions from preceding discussions. Section 2 pointed out that legal materials say precious little about how much market power is required. In the case just considered, the answer (as a point estimate) is: however much is necessary for the anticompetitive strategy to be profitable. Subsection 3.1 casts doubt on the notion that the functional form should treat the level of market power lexicographically; a more continuous role is suggested here, once we make the realistic relaxations to the pure threshold formulation just mentioned. And subsection 3.2 offered a skeptical view of separability; here, we can see that the requisite level of market power itself depends on features of the action that determine its profitability, demonstrating substantial interaction between market power evidence and act evidence. (Additional interactions will appear throughout the remainder of this section.)

Our present example is hardly the only possibility. Greater market power need not imply that $p^{G}(e)$ is higher while $p^{L}(e)$ is unaffected, and sometimes $p^{L}(e)$ could even rise relatively more rapidly than does $p^{G}(e)$. Notably, procompetitive explanations may also depend on market power, including the prospect thereof. For example, suppose that a firm seeks to justify its low (perhaps below-cost) pricing as a strategy of product promotion. The plausibility of this description obviously depends on market power because any short-run profit sacrifice can only be recovered by charging a price above marginal cost later, and the greater the market power for the product, once established, the more profitable such ex ante promotion would be. ${ }^{18}$ Hence, the view that market power favors liability with regard to classification depends on the further assumption that it raises $p^{G}(e)$ relative to $p^{L}(e)$. In our initial case in which greater market power made the anticompetitive explanation more plausible and by stipulation had no effect on the likelihood of the procompetitive explanation, this was so, but once we allow the appeal of the procompetitive explanation also to be rising in market power, the situation changes: $p^{G}(e)$ may nevertheless rise relatively faster in market power than does $p^{L}(e)$, they may rise at the same relative rate, and $p^{G}(e)$ could even rise relatively more slowly in some ranges.

As stated at the outset of this subsection, it is an analytical mistake to see market power as favoring liability on classification grounds by arguing that, conditional on the act being anticompetitive, market power is likely to be high. This frequency is only half of the story. The

\footnotetext{
${ }^{18}$ Consider, for example, Internet start-ups in the past two decades that ran losses for many years, in some cases charging prices of zero, sometimes achieving multi-billion dollar market valuations before ever turning a profit.
} 
likelihood that a defendant firm has a CEO conditional on the act being anticompetitive is very close to one, yet the same is true with regard to the procompetitive explanation; the likelihood ratio is one, so the evidence is not probative. Consider another (non-market-power) example that makes the same point: a common belief for ages had been that exclusive dealing contracts must have long durations in order to be exclusionary, but not only has recent theory and evidence indicated that this is not necessarily so (e.g., Whinston 2006), but it also is often forgotten that prominent procompetitive explanations (often involving the inducement of investment) require a very long duration. Therefore, long duration may raise $p^{L}(e)$ by relatively more than it boosts $p^{G}(e) .{ }^{19}$ In all, we have seen that the relevance of market power - and any other evidence - to classification depends on how it bears relatively on the competing explanations under consideration.

Classification is central to many discussions in agency guidance statements and in individual cases. Market power may (but need not) have direct relevance here, although the foregoing makes clear that the traditional structure of the inquiry deviates sharply from sound analysis of the question. It does not make sense to assess market power first, in a vacuum, and match our estimate against some standardized threshold - after which we set market power to the side as we proceed to analyze the challenged practice. Nor is it appropriate when analyzing an act to ask in a vacuum whether it is anticompetitive and, if and only if it is, to consider procompetitive explanations.

The other major shortcoming emphasized in subsection 3.3.1 is that a proper cost-benefit test is concerned not only with $p^{G}(e)$ and $p^{L}(e)$ but also with the magnitudes of the welfare consequences associated with the prohibition of each type of act. If $G(e)$ and $L(e)$ were each constant across cases, they could be ignored. Moreover, if they were equal to each other in every case, then we could confine our attention to "getting it right," in the sense that liability would be assigned if and only if $p^{G}(e)>p^{L}(e)$. In the case of two mutually exclusive explanations, this corresponds to the preponderance of the evidence rule, under which liability turns on whether $p(e)>0.5$. The medical decision-making analogy sharply illustrates how poor these assumptions can be. Accordingly, in the next two subsections, we consider how market power in particular may bear on $G(e)$ and $L(e)$.

\subsubsection{Prohibition gain if anticompetitive: $G(e)$}

It has been mentioned that market power can take many senses, which may have different implications for different purposes. In examining how market power may bear on the magnitude of $G(e)$, the gain from prohibition of an anticompetitive act - or, the gain from deterrence in a setting involving the imposition of sanctions, the prospect of which influences ex ante behavior it is helpful to elaborate in this regard. Here, a distinction will be drawn between levels of market power and changes in market power, referred to as the market power delta, $M P^{\Delta}{ }^{20}$ Regarding levels, we may be interested in the level before or without the challenged practice ("pre”), denoted $M P^{\text {pre }}$, or the level after or with the practice ("post”), $M P^{\text {post }}$. Note that $M P^{4} \equiv$

\footnotetext{
${ }^{19}$ Analysis of tying can also raise this tension. On one hand, physical as opposed to contractual tying is often thought to be more suggestive of efficiency justifications. On the other hand, Whinston (1990) shows that in some cases physical tying may provide the necessary precommitment for an exclusionary strategy to be effective.

${ }^{20}$ The analysis in this subsection is inspired by and draws importantly on Kaplow and Shapiro (2007), to which Carl Shapiro contributed significantly in relevant respects (and in most others).
} 
$M P^{\text {post }}-M P^{\text {pre }}$. (Note further that an immediate implication of this definition is that $M P^{4}$ is falling in $M P^{\text {pre }}$, ceteris paribus. This mere accounting fact is nevertheless troubling in light of the common view is that liability is favored by higher market power, that market power is often understood to refer to its level, and the level in some contexts appears to refer to $M P^{\text {pre }}$.)

For concreteness, we might think of each of these measures as denominated in terms of the Lerner index that featured in our discussions in subsection 2.1, but other measures might be imagined as well. Indeed, a central theme of this article is that, because market power is relevant precisely on account of how it may influence the value of the key terms in our decision rule, the correct definition of market power is whatever works, that is, whatever intermediate indicator, derived from some subset of the evidence, is a sufficient statistic (or approximately so) for purposes of determining $p^{G}(e), p^{L}(e), G(e)$, and $L(e)$. And the answer(s) need not be the same for each factor, or across types of practices and pertinent anticompetitive and procompetitive explanations.

The most straightforward manner in which market power may be relevant to $G(e)$ is that $M P^{\Delta}$ might be said almost to define $G(e)$, or, perhaps instead or as well, $p^{G}(e)$. Specifically, if $M P^{\Delta}>0$, we might say that $p^{G}(e)=1$, and that if $M P^{\Delta} \leq 0$, then $p^{G}(e)=0$. Or, admitting some uncertainty in our estimate of $M P^{\Delta}$, we might state $p^{G}(e)$ as an increasing function of $M P^{4}$. The example of horizontal mergers comes to mind. Of course, this sort of statement, while having the virtue of making sense, has the limitation of adding little value. If the difficulty is in figuring out the presence of anticompetitive effects, it is not helpful to state that they are an increasing function of estimated anticompetitive effects.

Return now to the initial part of our statement regarding the relationship between $M P^{4}$ and $G(e)$. Here, something meaningful and significant is at stake. Setting aside likelihoods taking our estimate of $p^{G}(e)$ to be fixed - the imposition of liability is more desirable the greater is $M P^{\Delta}$ conditional on our act in fact being anticompetitive. In simple terms, if the magnitude of the anticompetitive effect is greater (when indeed the practice is abusive), the case for liability is stronger. This point is fairly obvious, but nevertheless important.

One way that market power may bear on the magnitude of $G(e)$ is because market power may bear on the magnitude of the price effect of a challenged practice. But the manner in which this channel operates depends on the context and may involve some unexpected subtleties. For example, Salop and Scheffman (1983) analyze of the price effect of a strategy that raises rivals' costs using the familiar dominant firm model used in subsection 2.1. ${ }^{21}$ Their formula translating a unit increase in rivals' marginal costs into a price increase not surprisingly depends on the same three factors as does the Lerner index in this setting. But if one looks further, it becomes apparent that the Lerner index is not a sufficient statistic for the pertinent factor, not even close. Although the magnitude of the price increase is falling in $\left|\varepsilon_{d}\right|$ (the magnitude of the market elasticity of demand), as one would expect, it is rising, not falling, in $\varepsilon_{r}$ (rivals' supply elasticity) and falling, not rising, in $S$ (the dominant firm's market share). ${ }^{22}$ The intuition is that, the more that rivals' supply response initially constrains the dominant firm's price elevations (the lower its initial market power in this respect), the greater is the price augmentation effect of raising rivals'

\footnotetext{
${ }^{21}$ They analyze the price effect to identify a sufficient condition for the profitability of a raising rivals' costs strategy, which bears on $p^{G}$, the subject of subsection 3.3.2. Often the magnitude of the plausible price effect will bear both on classification and on the magnitude of harm conditional on the act being anticompetitive.

${ }^{22}$ Their formula appears at page 269. Further elaboration will be featured in my in-progress project, "On the Relevance of Market Power.”
} 
marginal costs. In this setting, when we decompose this standard market power measure, all of its components are relevant to the magnitude of the price increase, but two of the three have the opposite sign from what is implied by the view that a higher level of market power implies a larger $G(e)$.

There is a second important channel through which market power can be - and fairly broadly is - relevant to liability via its influence on the magnitude of $G(e)$. Because we imagine that $G(e)$ is in units of social welfare (or some related construct), we need to map, say, a given hypothesized price increase (measured perhaps in percentage terms, as with the Lerner index, or perhaps in euros or dollars) into welfare. This translation may depend on levels of market power. $^{23}$

To fix ideas, consider the impact of a marginal increase in price (a positive but very small $M P^{4}$ ). Starting from the point at which price equals marginal cost, the marginal deadweight loss is zero. If the initial price is above marginal cost, marginal deadweight loss is positive, and its magnitude is increasing with the initial price level. That is, the marginal welfare loss, which might be taken as $G(e)$, is rising in $M P^{p r e}$ (which, for an infinitesimal change, essentially equals $M P^{\text {post }}$.

Next, suppose instead that our welfare measure, captured by $G(e)$, is consumer surplus. For a marginal, one unit increase in price, the reduction in consumer surplus simply equals the quantity. Ceteris paribus, quantity is falling in price. Hence, the magnitude of the marginal increase in $G(e)$ is now falling in $M P^{\text {pre }}$ (equivalently, $M P^{\text {post }}$ ).

For both of these welfare measures, $G(e)$ depends on the level of market power (as well as on $M P^{4}$, as previously noted). The sign of the marginal effect depends on which welfare measure is chosen. As an aside, it is interesting that horizontal merger guidelines typically indicate that challenges are more likely the higher is the change in the $\mathrm{HHI}$ (which is unsurprising, viewing this delta as a proxy for $M P^{4}$ ) and the higher is the post-merger HHI, which is often understood as a proxy for $M P^{\text {post }}$. As just explained, the latter is as one would expect under a total surplus welfare standard, yet some merger guidelines and most of those interpreting them assert that they are implementing a consumer surplus standard, which, by the foregoing logic, would have the likelihood of a challenge falling in $M P^{\text {post }}$. To be sure, there are other reasons for placing positive rather than negative weight on the post-merger HHI, but one would have to believe that they were generally present and of sufficient magnitude to outweigh the countervailing effect just described.

More broadly, most statements of competition law - whether in treatises, agency guidance, court opinions, or commentary - take the level of market power to be important. A central example, the one used in most of this article, relates to abuse of dominance or monopolization, where the first element is taken to be a high level of market power (although typically stated, problematically, as a market share). As just explained, one justification for the market power level being systematically relevant, and positively correlated to the desirability of liability, would be as a translation from some $M P^{\Delta}$ to a welfare delta, where welfare is taken to be total surplus. Other justifications might involve classification, as explained in the preceding subsection. In any event, there has been insufficient attention to determination of the magnitude of $G(e)$, however understood, and to how its magnitude is influenced by market power in various senses. And, more specifically, whether we are considering $p^{G}(e), p^{L}(e), G(e)$, or $L(e)$,

\footnotetext{
${ }^{23}$ Discussion of this point draws on Kaplow (2012, 2013).
} 
it is often unclear whether the level of market power being contemplated is $M P^{\text {pre }}$ or $M P^{\text {post }}$, if indeed the level of market power is indeed the relevant sense of market power.

\subsubsection{Prohibition loss if procompetitive: $L(e)$}

The main purpose of this subsection is to draw attention to the simple but often neglected point that, in plausible settings, $L(e)$ and not just $G(e)$ may depend on market power in various guises. Of particular concern, factors that indicate greater market power may likewise imply that $L(e)$ is larger. For example, if a practice covers more of the market because the firm implementing it has greater market power, then if the practice in fact has procompetitive effects, the social loss from prohibition may be correspondingly higher. If a firm is strongly dominant, then if its challenged act is indeed innovative, as it asserts, rather than exclusionary, prohibition (or discouragement through the prospect of sanctions) would be particularly detrimental.

The implication of this possibility is straightforward. Whether we are examining just $G(e)$ and $L(e)$ - or are also including the full decision criterion from subsection 3.3.1 that includes $p^{G}(e)$ and $p^{L}(e)$ as well - the effect of market power on the desirability of holding a firm liable for a challenged practice is more complicated than ordinarily contemplated. Before we noted that sometimes $p^{L}(e)$ may be rising relatively more rapidly with market power than is $p^{G}(e)$. We now add the possibility that $L(e)$ may be rising. Overall, the relationship between market power and the optimality of liability may be positive or negative, need not be monotonic, and, even when it is monotonically increasing, the magnitude of the total derivative will vary greatly across contexts. Moreover, as emphasized in the preceding subsection, market power can mean many things ( $M P^{\text {pre }}, M P^{\text {post }}, M P^{4}$, or perhaps something else), and with respect to each of them, the pertinent derivative may differ in sign and magnitude. Therefore, our earlier reduced form $f(M P, A)$, whether taken to be lexicographic as in Figure 2 or to allow continuous tradeoffs as in Figure 1, is a gross oversimplification of how market power may be relevant to an optimal decision on liability.

\subsection{Illustration}

Because much of section 3 has been fairly abstract, it is useful to offer a somewhat extended example. Given the large number of permutations of plausible market power influences and the wide variety of potentially exclusionary practices and competing hypotheses, this subsection presents and partially analyzes a simple and special case that illustrates a handful of the possibilities.

Predatory pricing and many other forms of arguably abusive practices involve a short-run profit sacrifice in order to generate a larger, long-run profit increase. In order for the alleged exclusionary action to be profitable and thus rational, the following sort of constraint must be satisfied (e.g., Ordover and Saloner 1989):

$$
\pi^{C}-\pi^{E}<\frac{\delta\left(\pi^{M}-\pi^{C}\right)}{1-\delta} .
$$

The left side depicts this short-run profit sacrifice, showing the difference between the "competitive" or accommodating level of profit $\left(\pi^{C}\right)$ and the lower level of profit $\left(\pi^{E}\right)$ if the aggressive, allegedly exclusionary action is undertaken. The right side shows the difference

between the "monopoly" profit $\left(\pi^{M}\right)$ and the competitive profit, taken to begin in the next period 
(hence the discount factor $\delta$ ), and assumed to continue indefinitely (explaining the $1-\delta$ in the denominator).

This familiar individual rationality constraint (often discussed in competition policy discourse as a recoupment requirement) embodies a number of simplifications. The competitive or accommodating level of profit $\left(\pi^{C}\right)$ is taken to be the same in the initial period and in all subsequent periods. Note also that the use of the term "competitive" is only meant in a comparative sense and, as we shall see, is not meant to rule out less than fully competitive outcomes. Likewise, the "monopoly" profit $\left(\pi^{M}\right)$ is simply the heightened level of future profit as a consequence of taking the exclusionary action.

Before exploring the relevance of market power in assessing whether this constraint is likely to hold, it is useful, following subsection 3.3.1, to articulate as well the procompetitive explanation(s). For example, seemingly aggressive short-run pricing may be explained not only by predation but also by product promotion or moving down a learning curve (in which case the dynamic analogue to short-run marginal cost accounts for the reduction in future costs and hence is lower, making the price cut less aggressive relative to a marginal cost benchmark).

Observe that both of these explanations are associated with an individual rationality constraint under which there must be a profit increase in future periods sufficient to justify the short-run sacrifice. ${ }^{24}$ Indeed, the individual rationality constraint for these procompetitive strategies takes the same form, and may have much the same content, as the individual rationality constraint for the exclusionary strategy, here, predatory pricing. Going further, this standard individual rationality constraint is just the condition for the profitability of a generic investment. After all, an investment (say, in a new plant) is simply an expenditure today that has no (or modest) immediate payoff, but changes conditions going forward such that future profit flows will be higher. Investments are profitable to undertake when their cost (short-run profit sacrifice) is exceeded by the discounted value of the augmentation to future profits.

The immediate implication of this observation is that, as an initial matter, testing whether this individual rationality constraint is satisfied is not at all diagnostic in distinguishing abusive behavior from the particular (aforementioned) procompetitive explanations in this setting. Therefore, whatever is the relationship, if any, between market power and whether this constraint holds, market power will similarly be nondiagnostic.

There are, of course, other benign explanations for which determination of whether this constraint is satisfied would be diagnostic. If an important competing hypothesis is that the act does not in fact involve a price reduction below the competitive (accommodating) level, then there is no short-run profit sacrifice that needs to be recouped. Hence, in comparing this alternative hypothesis, the relative likelihood of predation is rising in the likelihood that this constraint is satisfied. ${ }^{25}$ Consideration of a variety of possible competing procompetitive explanations in this example illustrates the previous claim that being explicit about possible alternative hypotheses can be important in indicating what evidence should be collected and in making a decision regarding liability. In contrast, the failure to specify the relevant competing

\footnotetext{
${ }^{24}$ The willingness to price below (apparent) short-run marginal cost in order to accelerate learning when there is the prospect of future market power plays a central role, for example, in Benkard's (2004) study of the commercial aircraft industry.

${ }^{25}$ Intermediate cases raise interesting tradeoffs with regard to litigation positions. The more the challenger shows that the price is low relative to cost, the stronger is the indication that the price cut is predatory (relative to the competing hypothesis of simple accommodation), strengthening the case for liability, but the greater the recoupment requirement, weakening the case for liability. Equivalently, when a defendant claims that its price is not very low in fact, it weakens the case for liability in that regard but relaxes the implied recoupment requirement.
} 
hypothesis can lead us astray - such as by placing great weight on whether this constraint seems to be satisfied in a setting in which that is not diagnostic.

Let us now suppose that, given the relevant procompetitive explanation, whether this constraint is satisfied is significantly diagnostic. We are then interested in knowing how market power bears on the constraint. In examining the inequality, we can immediately see that there is a challenge: it seems plausible that higher market power in some relevant senses would raise all of the $\pi^{j}$ terms. If that were so, and, suppose further, greater market power implied that each was higher proportionately, there would be no effect on the constraint. (There would be an effect with regard to magnitudes: if the constraint is satisfied, for example, doubling both sides of the inequality doubles the difference. But whether or not the inequality holds is unaffected.) Hence, for market power to be relevant in this fashion, it must be true that higher market power has a differential relative effect on these terms. ${ }^{26}$ We will now consider some possibilities.

Most obviously - and perhaps what most have in mind - greater market power may imply (only) that $\pi^{M}$ is higher, which raises the right side of the inequality and therefore makes it more likely to be satisfied. This would correspond to greater market power in the sense of the level with the act, that is, $M P^{\text {post }}$.

However, greater market power might imply, in addition or instead, that $\pi^{C}$ is higher. This would correspond to greater market power in the sense of the level without the act, that is, $M P^{p r e}$. In that case, the constraint would be harder to satisfy, which is to say that greater market power would weaken the case for liability, the opposite of conventional wisdom. ${ }^{27}$ This point is even clearer if we rearrange the prior expression as follows:

$$
\pi^{C}<\delta \pi^{M}+(1-\delta) \pi^{E} \text {. }
$$

Moreover, the possibility that higher market power in the sense of $M P^{p r e}$ may weaken the case for liability in our setting is not far-fetched. Some features ordinarily associated with greater market power might suggest that, in the absence of exclusion, the incumbent and rival would interact less aggressively, implying a higher $\pi^{C}$, which makes the short-run sacrifice greater and the profit augmentation conditional on success smaller. Another sense in which $M P^{\text {pre }}$ may be lower is an absence of tangible barriers to entry. It is in precisely such cases that certain forms of predation are attractive, for the purpose of such predation is to erect an entry barrier that would not otherwise be present (Easley, Masson, and Reynolds 1985). That is, a lower level of $M P^{\text {pre }}$, indicating a lower level of $\pi^{C}$, favors predation, ceteris paribus. Restating this point with both signs reversed: higher market power in this sense makes the predation hypothesis less convincing.

This discussion reinforces a number of earlier lessons. First, it can be helpful to be explicit about both anticompetitive and procompetitive explanations: just how it is imagined that the allegedly abusive act will cause anticompetitive harm and what is (are) the procompetitive explanation(s). In some settings, only when both types of explanation are well articulated can we begin to trace the channels by which market power may be relevant. Here, we have seen

\footnotetext{
${ }^{26}$ As elaborated earlier in this section, market power could also be relevant in other ways. Here, we are confining attention to how market power affects the constraint.

${ }^{27}$ Note that, under a very loose (heuristic) interpretation in which $M P^{\text {post }}=\pi^{M}$ and $M P^{\text {pre }}=\pi^{C}$, the right side of our constraint can be rewritten as $\delta M P^{\Delta} /(1-\delta)$. This substitution illustrates the point that, when the focus is on $M P^{\Delta}$, a greater $M P^{\text {pre }}$ may disfavor liability, although here we also have a second channel by which this comes about because $M P^{\text {pre }}$ also appears on the left side of our constraint. In addition, this way of rewriting the constraint makes it a function of $M P^{\text {pre }}$ and $M P^{\Delta}$, whereas loose discussions of the relevance of market power with regard to exclusion tend to suggest that the measure of concern is $M P^{\text {post }}$.
} 
straightforward cases in which market power is nondiagnostic and in which greater market power may disfavor liability, all in a realm in which substantial market power is taken to be of great importance in establishing liability. Conventional wisdom may usually be correct, but whether this is so depends on what the competing hypotheses are, which senses of market power are being considered, which channels of possible relevance are under examination, and various other factors.

\section{Conclusion}

Market power is central to many rules of competition law and plays an important role in most cases other than cartel prosecutions. The market definition paradigm has long been the dominant method of determining market power, and market share threshold tests, which would seem to require a market definition, are the standard means of articulating market power requirements. These methods, however, are at odds with industrial organization economics. There exists no valid way to infer market power from market shares in redefined (nonhomogeneous goods) markets, and the only means of determining which of two market definitions is superior is by reference to an already formulated best estimate of market power, rendering market definition pointless and introducing avoidable error. Market share tests for market power suffer as a matter of empirics, because a particular market share does not indicate any determinate degree of market power, and as a matter of policy, because they do not embody any judgment of how much market power should be required. The good news is that industrial organization economics has for some time been developing more direct means of estimating market power (e.g., Baker and Bresnahan 1988, Nevo 2001) and there often are other means of estimating market power, such as by examining firms' documents and querying market participants. Although all these approaches have limitations, it cannot help to substitute or supplement them with an approach that is incoherent and is parasitic on these very methods.

The appropriate role of market power in competition policy poses a different sort of challenge: surprisingly little research systematically illuminates the channels by which market power is relevant. Typically, market power is viewed as a separable element in an offense. The implicitly assumed functional relationship between market power and liability does not, on reflection, appear to be a reasonable approximation of how market power matters in most settings. An appropriate analysis begins by recognizing the familiar point that competition cases involve a tradeoff of false positives and false negatives. To make such a tradeoff, it is important as an initial matter to identify the most plausible anticompetitive and procompetitive explanations. Only then can one determine how any evidence, including evidence pertaining to market power, bears on the relative likelihoods. Moreover, market power may affect both the social harm of anticompetitive practices (if indeed such are present) - and hence the welfare gain from prohibition or deterrence - and the social benefit of procompetitive acts (if that is what we are examining) - and thus the welfare cost from denying permission or contributing to the chilling of such behavior. All of these components must be examined in order to ascertain whether, how, and in what sense market power may be relevant. Perhaps the level of market power (maybe with, or instead without the alleged anticompetitive act) informs classification or the magnitude of social harm. Sometimes the market power delta will be an important component of harm. And perhaps other aspects of market power, or none at all, will prove

relevant. Moreover, market power does not always indicate that the anticompetitive explanation is more likely, and sometimes greater market power may also imply a greater social cost of false 
positives. In all, market power is not even approximately a sufficient statistic (in the sense of Chetty 2009) for purposes of assigning liability. ${ }^{28}$ A number of these points were illustrated by reference to the rationality constraint for predatory pricing.

The important symbiosis between industrial organization economics and competition policy and practice has long been recognized and is significantly, albeit incompletely, instantiated in competition regimes throughout the world. Ongoing research in industrial organization economics, both theoretical and empirical, has great potential to contribute further, and market power is a realm where many significant avenues have not been fully identified. The framework offered here is meant to be suggestive of where some of the strongest needs lie and some of the greatest opportunities for progress may be located.

\section{References}

Baker, J.B., Bresnahan, T.F., 1985. The gains from merger or collusion in product-differentiated industries. J. Indus. Econ. 33, 427-444.

Baker, J.B., Bresnahan, T.F., 1988. Estimating the residual demand curve facing a single firm. Intl. J. Indus. Org. 6, 283-300.

Benkard, C.L., 2004. A dynamic analysis of the market for wide-bodied commercial aircraft. Rev. Econ. Stud. 71, 581-611.

Chetty, R., 2009. Sufficient statistics for welfare analysis: a bridge between structural and reduced-form methods. Ann. Rev. Econ. 1, 451-488.

Easley, D., Masson, R.T., Reynolds, R.J., 1985. Preying for time. J. Indus. Econ. 33, 445-460.

European Union, 1997. Commission Notice on the Definition of Relevant Market for Purposes of Community Competition Law, O.J. (C 372).

European Union, 2004. Guidelines on the Assessment of Horizontal Mergers under the Council Regulation on the Control of Concentrations between Undertakings, O.J. (C 31), 5-18.

European Union, 2005. DG Competition Discussion Paper on the Application of Article 82 of the Treaty to Exclusionary Abuses.

Farrell, J., Shapiro, C., 1990. Horizontal mergers: an equilibrium analysis. Am. Econ. Rev. 80, 107-126.

Farrell, J., Shapiro, C. 2010. Antitrust evaluation of horizontal mergers: an economic alternative to market definition. B.E. J. Theoretical Econ. 10(1) (Policies and Perspectives), Article 9.

Harris, B..C., Simons, J.J., 1989. Focusing market definition: how much substitution is necessary? Res. Law \& Econ. 12, 207-226.

Kaplow, L., 2010. Why (ever) define markets? Harvard Law Rev.124, 437-517.

Kaplow, L., 2011a. Market definition and the merger guidelines. Rev. Indus. Org. 39, 107-125.

Kaplow, L., 2011b. Market share thresholds: on the conflation of empirical assessments and legal policy judgments. J. Competition Law \& Econ. 7, 243-276.

\footnotetext{
${ }^{28}$ As a clarification, note that this conclusion does not deny the ability to screen out large numbers of very weak cases by reference to market power. In many instances, it will be fairly clear that market power is negligible in every sense, including $M P^{\text {post }}$ and thus, necessarily, $M P^{\Delta}$, so that considerations of administrative costs and even a mild concern for false positives will warrant a prompt end to the investigation. Note further that the view that market definition is helpful in such cases - because often it is obvious that the correct market definition is quite broad - is misleading: we can only be confident that a narrow market definition is wrong if we already know that market power is low, as explained in subsection 2.2, so market definition does not, on reflection, assist in screening.
} 
Kaplow, L., 2011c. On the optimal burden of proof. J. Polit. Econ. 119, 1104-1140.

Kaplow, L., 2011d. Optimal proof burdens, deterrence, and the chilling of desirable behavior. Am. Econ. Rev. Pap. \& Proc. 101(3), 277-280.

Kaplow, L., 2012. On the choice of welfare standards in competition law, in D. Zimmer, Goals of Competition Law. Edward Elgar: Cheltenham, UK..

Kaplow, L., 2013. Competition Policy and Price Fixing. Princeton University Press: Princeton, NJ.

Kaplow, L., 2014. Likelihood ratio tests and legal decision rules. Am. L. \& Econ. Rev. 16, 1-39. Kaplow, L., Shapiro, C. 2007. Antitrust, in A.M. Polinsky \& S. Shavell, Handbook of Law and Economics, vol. 2. Elsevier: Amsterdam.

Landes, W.M., Posner, R.A., 1981. Market power in antitrust cases. Harvard Law Rev. 94, 937996.

Nevo, A., 2001. Measuring market power in the ready-to-eat cereal industry. Econometrica 69, 307-342.

Ordover, J.A., Saloner, G., 1989. Predation, monopolization, and antitrust, in R. Schmalensee \& R.D. Willig, Handbook of Industrial Organization, vol. 1. Elsevier: Amsterdam.

Salop, S.C., Scheffman, D.T., 1983. Raising rivals’ costs. Am. Econ. Rev. Pap. \& Proc. 73(2), 267-271.

Stigler, G.J., 1940. Notes on the theory of duopoly. J. Pol. Econ. 48, 521-541.

U.S. Department of Justice, 2008. Competition and Monopoly: Single-Firm Conduct Under Section 2 of the Sherman Act

U.S. Department of Justice and Federal Trade Commission, 2010. Horizontal Merger Guidelines.

Whinston, M.D., 1990. Tying, foreclosure, and exclusion. Am. Econ. Rev. 80, 837-859.

Whinston, M.D., 2006. Lectures on Antitrust Economics. MIT Press: Cambridge, MA. 